\title{
A metodologia do marco lógico e a gestão da informação: um estudo de caso para Tunas-PR
}

\author{
The logical framework approach and the information \\ management: a case study for Tunas-PR
}

Edmeire Cristina PEREIRA'

Ronald Jesus da CONCEIÇÃO²

Blas Enrique CABALLERO NUNEZ ${ }^{3}$

\section{RESUMO}

Apresenta a Metodologia do Marco Lógico (MML) como uma ferramenta para análise de formulação e avaliação de políticas públicas, de programas e projetos de desenvolvimento sustentável, com vistas ao acesso a financiamentos de projetos por organismos internacionais. São caracterizados o histórico, as bases conceituais da Comissão Econômica para a América Latina e Caribe (CEPAL) e da Agência Sueca de Cooperação Internacional para o Desenvolvimento (ASDI), as etapas e a estrutura da MML, bem como suas vantagens e desvantagens. Evidencia que o papel da Gestão da Informação para a MML é muito importante, na medida em que pode colaborar com empreendedores e formuladores de políticas públicas de desenvolvimento sustentável, no tocante ao levantamento de fontes primárias e secundárias para a tomada de decisões; gestão da propriedade intelectual (como o registro de marcas e o depósito de patentes, por exemplo); transferência de tecnologia e colaboração na criação de sistemas de informações econômico-sociais e ambientais para o desenvolvimento sustentável, principalmente, de municípios de baixo IDH-M.

Palavras-chave: metodologia do marco lógico; gestão da informação; desenvolvimento sustentável; planejamento regional; políticas públicas.

\section{ABSTRACT}

It presents the Logical Framework Approach (LFA) as a tool for formulation and evaluation analysis of public policies, programmes and projects for sustainable development, in order to access projects funding through

1 Professora Assistente III, Curso de Gestão da Informação, Universidade Federal do Paraná - (UFPR). Vice-Coordenadora do Laboratório de Ecossocioeconomia da UFPR. Av. Prefeito Lothário Meissner, 632, Jardim Botânico, 80210-170, Curitiba, PR. Correspondência para/Correspondence to: E.C. PEREIRA.E-mail: <edmeire@ufpr.br>.

2 Acadêmico, Curso de Ciências Econômicas, Universidade Federal do Paraná - (UFPR). Membro colaborador do Laboratório de Ecossocioeconomia da UFPR Bolsista do Centro de Pesquisas Econômicas (CEPEC) da UFPR. Curitiba, PR. E-mail: <ronald.jesus@ufpr.br>.

3 Professor Adjunto IV, Curso de Ciências Econômicas, Universidade Federal do Paraná (UFPR). Coordenador do Laboratório de Ecossocioeconomia da UFPR. Membro Colaborador do CIFLOMA/Engenharia Florestal da UFPR. Curitiba, PR. E-mail: <blas@ufpr.br>.

* Os autores agradecem ao Prof. Dr. Fabio Dória Scatolin do Departamento de Ciências Econômicas da UFPR, por suas sugestões de melhoria ao manuscrito.

Recebido em 29/2/2008 e aceito para publicação em 13/8/2008. 
international organizations. The historical, the conceptual basis of the Economic Commission for Latin America and Caribbean (ECLAC) and the Swedish Agency for International Development Cooperation (SADI), the steps and structure of the LFA as well as their advantages and disadvantages are thereby characterized. It evidences the important role of the Information Management for the LFA as it can collaborate with entrepreneurs and formulators of public policies for sustainable development, aiming the survey of primary and secondary sources for decisions taking; intellectual property management (such as the registration of trade marks and patents fillings, e.g.) technology transfer and collaboration in the creation of information systems for economic-social and environmental sustainable development, mainly in low HDI-M municipalities.

Keywords: logical framework approach; information management; sustainable development; regional planning; public policies.

\section{INTRODUÇÃO}

"A política é a arte de procurar problemas, encontrá-los, fazer o diagnóstico errado e depois aplicar mal os remédios errados."

(Groucho Marx)

O maior desafio de nossa época é reduzir a pobreza do mundo à metade. $E$, para que isto ocorra, são requisitos a cooperação e a sustentabilidade; cabendo aos países a responsabilidade pelo seu próprio desenvolvimento (ASDI, 2006).

Daí, então, a necessidade de evidenciarmos metodologias para a formulação e avaliação de políticas públicas, como parâmetros científicos para o planejamento, a execução e a avaliação de programas e projetos, principalmente, de desenvolvimento regional sustentável.

Como já tivemos a oportunidade de mencionar em artigo anterior na Transinformação, "[...] embora seja reconhecida sua importância, pouco ainda se estuda e se utiliza (pelo menos, no Brasil) de metodologias para Gestão da Informação, junto às indústrias, no comércio e nos serviços" (Pereira, 2003, p.304). Menos, ainda, se estuda e se aplica a Metodologia do Marco Lógico (MML) no curso de Gestão da Informação da Universidade Federal do Paraná (UFPR). Verifica-se, portanto, a necessidade de uma discussão inicial dos principais pressupostos, estrutura e princípios dessa metodologia, que, acreditamos, possa ser extremamente útil aos formuladores de políticas públicas de desenvolvimento econômico, bem como aos formuladores de políticas públicas de informação pelo país, em contextos que requeiram análises profundas de programas e projetos para os fins de financiamento. Certamente, aos formuladores de políticas para a iniciativa privada, também.

Nosso primeiro contato com o tema da MML ocorreu com a leitura do Caderno de Notícias da IFLA, ou seja, do IFLA/LAC NOTíCIAS No. 48, JUNIO 2006. Naquela publicação (Zapata 2006, p. 13-14), havia uma nota sobre uma Oficina (Taller) sobre Marco Lógico, em Fortaleza, capital do Ceará, de 20 a 22 de março de 2006, com uma especialista consultora da Agência Sueca de Cooperação Internacional para o Desenvolvimento - (ASDI) - Sra. Maria Holmqvist, aos membros do Comitê Permanente da Seção IFLA-LAC e com o apoio do Programa ALP.

Como, infelizmente, não pudemos participar de tal Oficina na Região Nordeste brasileira, logo fomos procurar um especialista no tema em nossa Universidade - UFPR, em Curitiba. Tivemos, então, o prazer e o privilégio de conhecer o Prof. Dr. Fábio Dória Scatolin, do Departamento de Economia da UFPR, que é um profundo conhecedor dessa MML, bem como de outras, além de ter tido experiência políitica junto ao Governo do Estado do Paraná, como Diretor Geral da Secretaria de Planejamento, sendo inclusive, docente responsável pela disciplina Metodologia para Formulação e Avaliação de Políiticas Públicas, do Curso de Especialização em Formulação e Gestão de Políticas Públicas - Turma A - ofertado pelo Departamento de Contabilidade, do Setor de Ciências Sociais Aplicadas, em 2006. Naquela ocasião, começamos a freqüentar as aulas do Prof. Scatolin que tratavam da MML, bem como a estudar seus materiais didáticos.

Ao mesmo tempo em que isso ocorria, participávamos (e participamos, ainda) do Grupo de Pesquisadores do Laboratório de Ecossocioeconomia da UFPR, liderado pelo Prof. Dr. Blas Enrique Caballero 
Nunez. Dessa parceria espontânea, fomos nos aprofundando nas questões do planejamento regional de desenvolvimento sustentável, na produção de artigos, na orientação de monografias de graduação e de pósgraduação e na participação, a convite, de Bancas de Monografias/Dissertações de Mestrado na UFPR, dentre outras atividades, junto aos cursos de Economia, Engenharia Florestal e Gestão da Informação.

Encontramo-nos diante de uma excelente oportunidade para conhecer (e dar a conhecer) a MML - cujo uso, ainda, não está suficientemente difundido no Brasil -, em especial, à classe bibliotecária, aos cientistas/gestores de informação bem como a leigos em geral. E, que, segundo (Zapata, 2006, p. 14) "es una herramienta que resulta indispensable para lograr el acceso al financiamiento de proyectos por parte de numerosos organismos internacionales".

Este artigo aborda, portanto, de maneira não exaustiva, um estudo de caso alusivo a Tunas-PR, no que tange à aplicação da MML. E, para que se compreenda o projeto que está em andamento naquele Município, o artigo foi estruturado da seguinte maneira: primeiro, noções sobre o paradigma do desenvolvimento sustentável; na seqüência, uma série de aspectos relevantes à $M M L$ e, por fim, uma breve discussão sobre o papel da gestão da informação no contexto dessa metodologia.

\section{O PARADIGMA DO DESENVOLVIMENTO SUSTENTÁVEL}

Para que possamos compreender corretamente as implicações do desenvolvimento sustentável, faz-se importante entender as noções de: a) crescimento; b) desenvolvimento; c) sustentabilidade. Para isso, fomos buscar um aporte teórico nos Professores Scatolin, ao qual já fizemos menção anterior neste artigo, e ao Prof. Titular da Universidade de São Paulo - (USP) Prof. Dr. José Eli da Veiga.

Começaríamos dizendo que, apesar do Plano de Aceleração do Crescimento - (PAC) (2007) citação ou data de implantação, o Brasil, ainda, vem crescendo muito lentamente, entre 3 ou 4\%, ao ano, enquanto a gigante do crescimento econômico, que é a China, cresce, a passos largos, entre 9 ou $11 \%$, ao ano. Perguntamos, então: por que não crescemos mais rapidamente? Com certeza, a resposta mais evidente, sem sombras de dúvidas, é por causa dos juros altos (10\%). No entanto, uma força global chamada de Revolução da Informação/Conhecimento vem contribuindo para o rebaixamento de preços, principalmente, dos produtos/bens intangíveis, tais como os computadores pessoais.

Diz-se que o crescimento econômico brasileiro não é sustentável, daí, a metáfora com o vôo da galinha (ave que voa, só que, rasteiramente). Perdemos, inclusive, para o Haiti, que cresce mais do que o Brasil! Na opinião de Scatolin (2006), é porque "o Brasil ficou muito atrelado à estabilização e reformas". Em sua explicação, a versão tradicional é aquela que privilegiou primeiro estabilizar, depois, privatizar e, por fim, liberalizar. Historicamente, de meados de 1930 a 1980, a estratégia adotada no país foi a de priorizar a Indústria (multinacionais, nacionais e estatais), do modelo da substituição das importações. Esse modelo, porém, começou a se esgotar no Governo Sarney (anos 1980). De 1994 para cá, optou-se, então, por: a) estabilização; b) reformas para a retomada do crescimento; c) retomada do crescimento.

Observe-se que, até agora, não estamos falando em desenvolvimento, e, sim, em crescimento. Cumprenos, então, distinguir crescimento de desenvolvimento e de sustentabilidade. Grosso modo, crescimento tem a ver com as riquezas de um país, com o seu Produto Interno Bruto (PIB), é um meio e não um fim; desenvolvimento tem a ver com o Índice de Desenvolvimento Humano (IDH), ou seja, com Saúde, Educação e Renda, basicamente; e sustentabilidade tem a ver com estabilidade, compatibilidade entre crescimento econômico e conservação dos ecossistemas ambientais e sociais. Nesse momento, é interessante olharmos o pensamento de Veiga (2007) sobre essas diferenças (Quadro 1): 
Quadro 1. Diferenças conceituais.

\begin{tabular}{|c|c|c|}
\hline CRESCIMENTO & DESENVOLVIMENTO & SUSTENTABILIDADE \\
\hline $\begin{array}{l}\text { Riqueza deve ser entendida como } \\
\text { valor de toda a base produtiva de } \\
\text { uma economia, compreendendo: o } \\
\text { capital criado pelo homem, os } \\
\text { recursos naturais, o conhecimento, } \\
\text { as habilidades e as instituições. } \\
\text { Assim, diz Sir Partha Dasgupta, o } \\
\text { desenvolvimento deveria ser visto } \\
\text { como crescimento da riqueza per } \\
\text { capita e não como crescimento do } \\
\text { PIB per capita(p.97). }\end{array}$ & 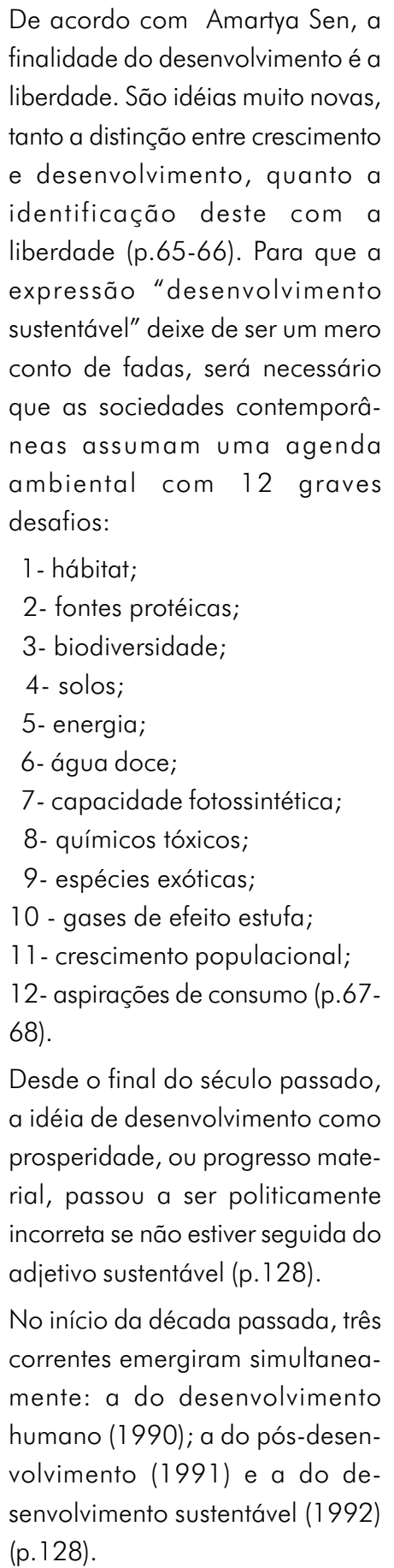 & $\begin{array}{l}\text { Até o final dos anos 1970, sustentabilidade } \\
\text { era um conceito circunscrito à biologia } \\
\text { populacional, usado principalmente em } \\
\text { pesquisas sobre manejo da pesca e das } \\
\text { florestas (p.61). A expressão "desenvolvi- } \\
\text { mento sustentável" foi publicamente } \\
\text { empregada pela primeira vez em agosto } \\
\text { de 1979, no Simpósio das Nações Unidas } \\
\text { sobre as Inter-relações entre Recursos, } \\
\text { Ambiente e Desenvolvimento. E começou } \\
\text { a se legitimar como o maior desafio desse } \\
\text { século quando Gro Harlem Brundtland, a } \\
\text { presidente da Comissão Mundial sobre } \\
\text { Meio Ambiente e Desenvolvimento, a } \\
\text { caracterizou como um "conceito político" } \\
\text { perante a Assembléia Geral da Organi- } \\
\text { zação das Nações Unidas (ONU) de 1987 } \\
\text { (p.61). } \\
\text { O adjetivo sustentável quer dizer: } \\
\text { manutenção de razoáveis taxas anuais de } \\
\text { aumento do PIB, sinônimo de: estável, } \\
\text { permanente, duradouro ou consolidado, } \\
\text { qualificar o processo de desenvolvimento } \\
\text { (compatibilizar crescimento econômico } \\
\text { com conservação dos ecossistemas). } \\
\text { Existe uma relação dialética entre } \\
\text { desenvolvimento e sustentabilidade e } \\
\text { crescimento econômico e conservação } \\
\text { ambiental (p.129). }\end{array}$ \\
\hline
\end{tabular}

Fonte: Veiga, 2007. 
Em linhas gerais, do ponto de vista regional, o desenvolvimento sustentável, é assim sintetizado por Amaral Filho (1996, p.37-38):

[...] pode ser entendido como um processo interno de ampliação contínua da capacidade de agregação de valor sobre a produção, bem como a capacidade de absorção da região, cujo desdobramento é a retenção do excedente econômico gerado na economia local e/ou a atração de excedentes provenientes de outras regiões [...]. Entretanto, o aspecto novo do processo, que traz à luz um novo paradigma de desenvolvimento regional endógeno, está no fato de que a definição do referido modelo de desenvolvimento passa a ser estruturada a partir dos próprios atores locais, e não mais pelo planejamento centralizado.

Até hoje, no Brasil, a "explicação tradicional" iá há muito tempo, não resolve mais os nossos problemas; vamos, portanto, para uma "explicação alternativa", segundo o pensamento de Scatolin (2006). A História e a Geografia importam cada vez mais, portanto o diagnóstico do crescimento deve ser o da situação atual: é preciso desenhar uma nova política e institucionalizar o crescimento. De que maneira? Um "caminho" possível, com certeza, é a adoção da MML, cujas etapas vão do diagnóstico para a estratégia.

que aconteceu no Brasil, certamente, nos últimos doze Planos Econômicos, foi o erro no diagnóstico. Aí, no décimo terceiro plano, veio o Plano Real. Ao se analisar um problema, na ótica da MML, deve-se, primeiro, olhar as suas conseqüências. Um exemplo: o desemprego. Sabemos que tem várias causas, desde renda per capita baixa, até às três últimas décadas de estagnação. Daí, deve-se traçar os objetivos e fins, e, por intermédio dos meios/ações (planos, programas, projetos), atacar as causas.

Brasil, hoje, encontra-se na fase das "Reformas de 2a Geração" (Scatolin, 2006), ou seja, seu foco de atenção, agora, está voltado para a efetividade de suas ações aos cidadãos. Efetividade aqui é entendida como conseqüência dos resultados, com o modelo de gestão orientado para resultados, com uma revalorização do Estado, com um Estado mais Regulador, com organizações mais flexíveis, descentralizadas, com responsabilização pelos resultados e participação cidadã. Como um exemplo, Scatolin (2006), propõe o que segue, no Quadro 2:

Quadro 2. Matriz do Marco Lógico.

\begin{tabular}{c|l|l|l}
\hline OBJETIVOS & INDICADORES & MEIOS DE VERIFICAÇÃO & HIPÓTESES \\
\hline FIM & & & \\
\hline PROPÓSITO & & & \\
\hline COMPONENTE & & & \\
\hline ATIVIDADES & & & \\
\hline
\end{tabular}

Fonte: Ortegon; Pacheco; Pietro, 2005, p. 70.

Além desses conceitos de eficácia, eficiência e efetividade, hoje em dia discute-se, também, o conceito de equidade, que é prover inclusão social e dar condições mínimas de sobrevivência às populações carentes.

Com esse desenvolvimento mais voltado para resultados, dois outros conceitos - governança e governabilidade - também chamam a atenção. "Governança é a capacidade financeira e administrativa de implementar as decisões políticas tomadas pelo Governo e Governabilidade é a capacidade política do governo de intermediar interesses, garantir legitimidade e, em última instância, governar" (Scatolin, 2006).

O planejamento tradicional difere da gestão do desenvolvimento, pois se comporta pelo "Ciclo da política tradicional (política pública)", onde há formulações e retroalimentações, assim (Scatolin, 2006). 


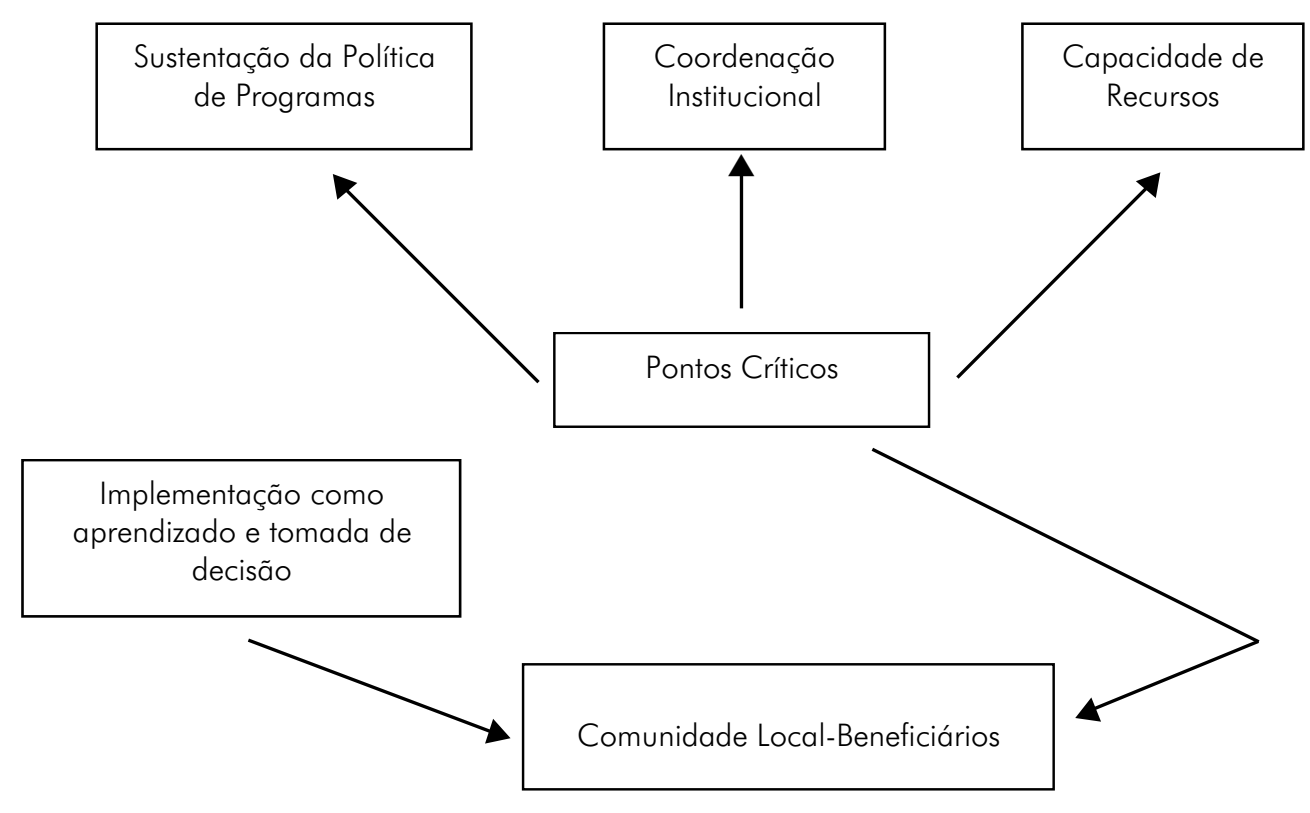

Aprendizado e tomada de decisão

Figura 1. Ciclo da política tradicional.

Fonte: Scatolin, 2006.

Quanto à gestão do desenvolvimento, na perspectiva da gestão integrada, difere do planejamento tradicional acima, nos seguintes pontos (Scatolin, 2006):

- objetivos: desenvolvimento integrado (visão territorial);

- mecanismos: crescimento visando a diversificação, inovação, flexibilidade da estrutura produtiva, numerosos projetos, criação de um entorno inovador;

- organização: gestão estratégica, administração descentralizada e Policy Networks e consórcios;

- agentes: agentes sociais locais, ONGs, PMEs, instituições supranacionais e Instituições supraregionais.

Pela Constituição Brasileira de 1988, a gestão integrada trabalha com: Planos Plurianuais (PPA) programas compostos por ações, e ações têm metas para quatro anos; Lei de Diretrizes Orçamentárias (LDO)
- define diretrizes para elaboração e execução de orçamentos; Lei Orçamentária Anual (LOA) - elaborada conforme as diretrizes da LDO e do PPA. Portanto o seu "Ciclo de gestão de programas" leva em consideração (Scatolin,2006): problema/demanda; planejamento; execução; monitoração; avaliação; revisão dos programas.

\section{A METODOLOGIA DO MARCO LÓGICO E O PROCESSO DE PLANEJAMENTO DO DESENVOL- VIMENTO SUSTENTÁVEL}

\section{Histórico}

O Método do Marco Lógico (MML), em Inglês, Logical Framework Approach, surgiu na década de 1970, no contexto de experiências em gerência de projetos e planejamento na área de cooperação internacional para o desenvolvimento. Diante da fragilidade dos meios de elaboração e 
acompanhamento de projetos, no ano de 1969 a United States Agency for International Development (USAID) contratou consultores que, com base em técnicas de gerenciamento de projetos, elaboraram a abordagem conhecida como Marco Lógico (Pfeiffer, 2000, p.81 apud Conceição, 2007, p. 28).

Atualmente, grande parte das organizações internacionais de financiamento e de cooperação para o desenvolvimento adota obrigatoriamente a Metodologia do Marco Lógico. No Brasil, a MML vem sendo utilizada de forma constante, por exemplo, pela Agência Brasileira de Cooperação (ABC), pelo Tribunal de Contas da União (TCU) e por todas as organizações públicas que postulam financiamento/apoio junto às principais instituições internacionais como a Organização das Nações Unidas (ONU), a União Européia (EU), o Fundo Monetário Internacional (FMI) e o Banco Interamericano de Desenvolvimento (BID). No caso do Estado do Paraná, a metodologia também é utilizada.

\section{Bases conceituais}

Forneceremos, a seguir, duas conceituações básicas sobre a MML: a primeira, de técnicos da Comissão Econômica para a América Latina e Caribe - (CEPAL) e a segunda, da Agência Sueca de Cooperação Internacional para o Desenvolvimento (ASDI), instituições de renome internacional:

a) La Metodologia de Marco Lógico es uma herramienta para facilitar el proceso de conceptualización, diseño, ejecución y evaluación de proyectos. Su énfasis está centrado en la orientación por objectivos, la orientación hacia grupos beneficiarios y el facilitar la participación y la comunicación entre las partes interesadas (Ortegón; Pacheco; Prieto, 2005, p. 13)

b) A MML é um conjunto de ferramentas agregadas que podem ser usadas no processo de elaboração, acompanhamento e avaliação de um projeto de planejamento. Essencialmente, a MML se define como: i) um instrumento de planejamento a partir de objetivos, análise, apreciação, acompanhamento e avaliação de projeto; ii) um meio auxiliar para a elaboração de uma análise lógica e estruturada para o planejamento; iii) um enquadramento que fornece a estrutura de coordenação para o processo de planejamento; iv) um instrumento que aborda os diversos elementos num processo de planejamento (problemas, objetivos, partes interessadas, plano de implementação, etc.); v) um meio auxiliar para criar participação/ responsabilidade/propriedade (ASDI, 2003, p.3).

\section{ETAPAS}

A adoção da MML inicia-se com a etapa de análise sobre o contexto do projeto, das partes interessadas/envolvidas e do problema abordado. $\mathrm{Na}$ segunda etapa, é necessário formular os objetivos e meios em relação à finalidade geral do plano, que, por sua vez, segue a elaboração do plano de atividades, plano de recursos e indicadores de objetivos realizados. Por fim, apresenta-se uma análise de riscos e dos pressupostos para a realização dos objetivos definidos (ASDI, 2003, p.5).

Para Lima (2003, p.3), inicialmente, a primeira etapa da MML consiste em contextualizar o planejamento em relação às partes interessadas/ envolvidas (público-meta), considerando o problema central a ser abordado (essa etapa da MML pode ser sustentada a partir do que se denomina de brainstorming process, considerando uma abordagem de investigação valorativa). Essa etapa é estruturada mediante a construção de uma árvore de problemas (Figura 2), tendo-se como intuito a percepção de um conjunto de deficiências, dentre as quais uma é identificada como problema central. 


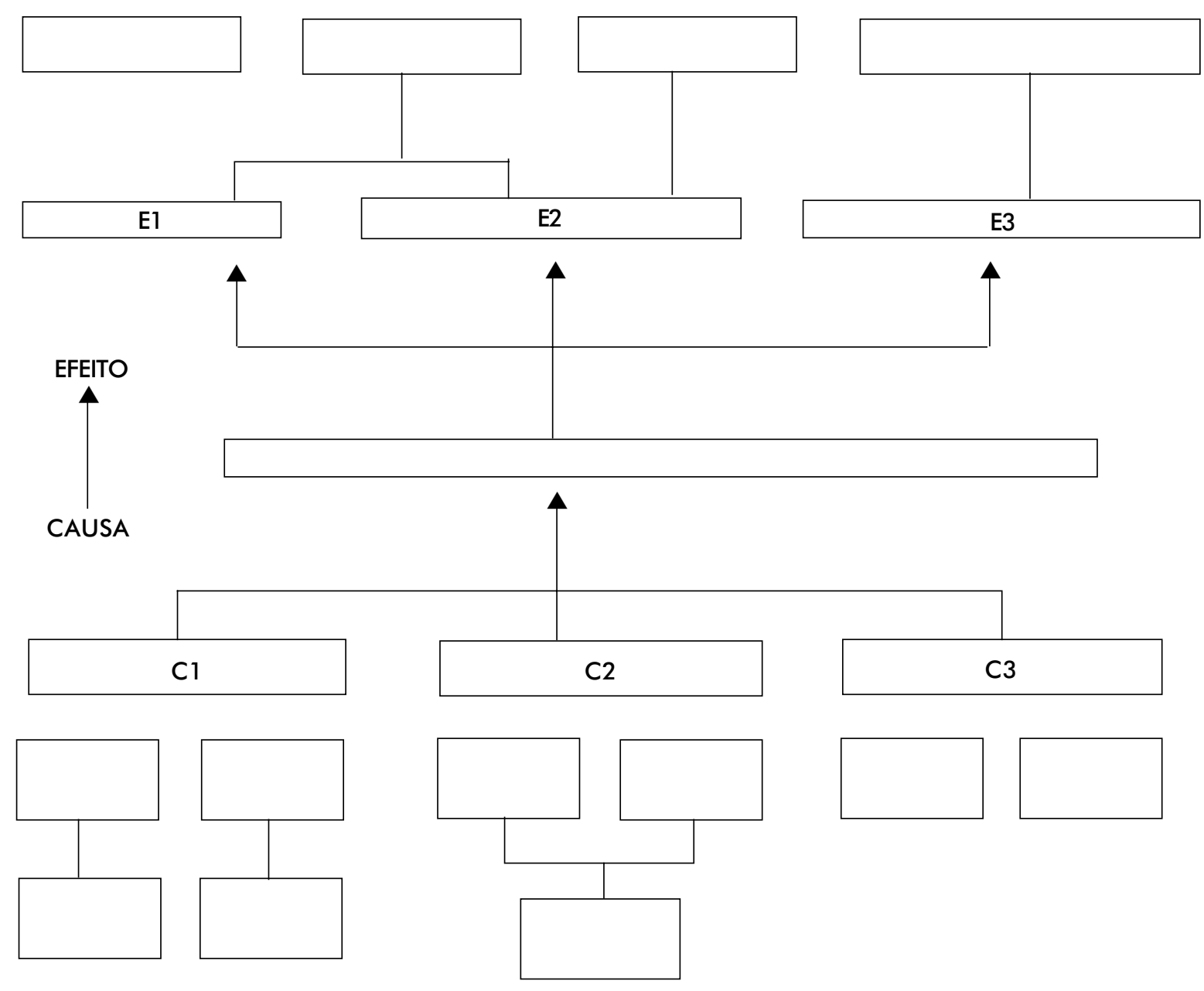

Figura 2. Árvore de problemas.

Fonte: Scatolin, 2006.

Legenda: $C=$ causas e $E=$ efeitos.

Numa segunda etapa, a MML consiste na análise de objetivos e meios, com a árvore de objetivos (soluções), que reproduz graficamente, de forma reduzida e auto-explicativa, as articulações envolvidas no sistema de planejamento.

Conforme argumentam Conceição e Caballero Nunez (2006, p.2), é necessário apresentar os objetivos (as soluções) fixados para o horizonte do plano e os meios de ação para alcançar a finalidade delimitada.

A terceira etapa da MML consiste em verificar os fatores que afetam de diversas formas as possibilidades de o planejamento alcançar os seus objetivos. Uma análise de eventuais fatores críticos possibilita uma boa avaliação de riscos e pressupostos com que o plano trabalha (ASDI, 2003, p. 12).

Quando essas três etapas forem executadas, a etapa de planejamento, na qual se apresenta a idéia do projeto de se converter em um plano operativo prático, tornar-se-á uma realidade possível (implementação do plano). Nessa hora, elabora-se uma Matriz do Marco Lógico. As atividades e os recursos são definidos e visualizados num certo horizonte de tempo. 


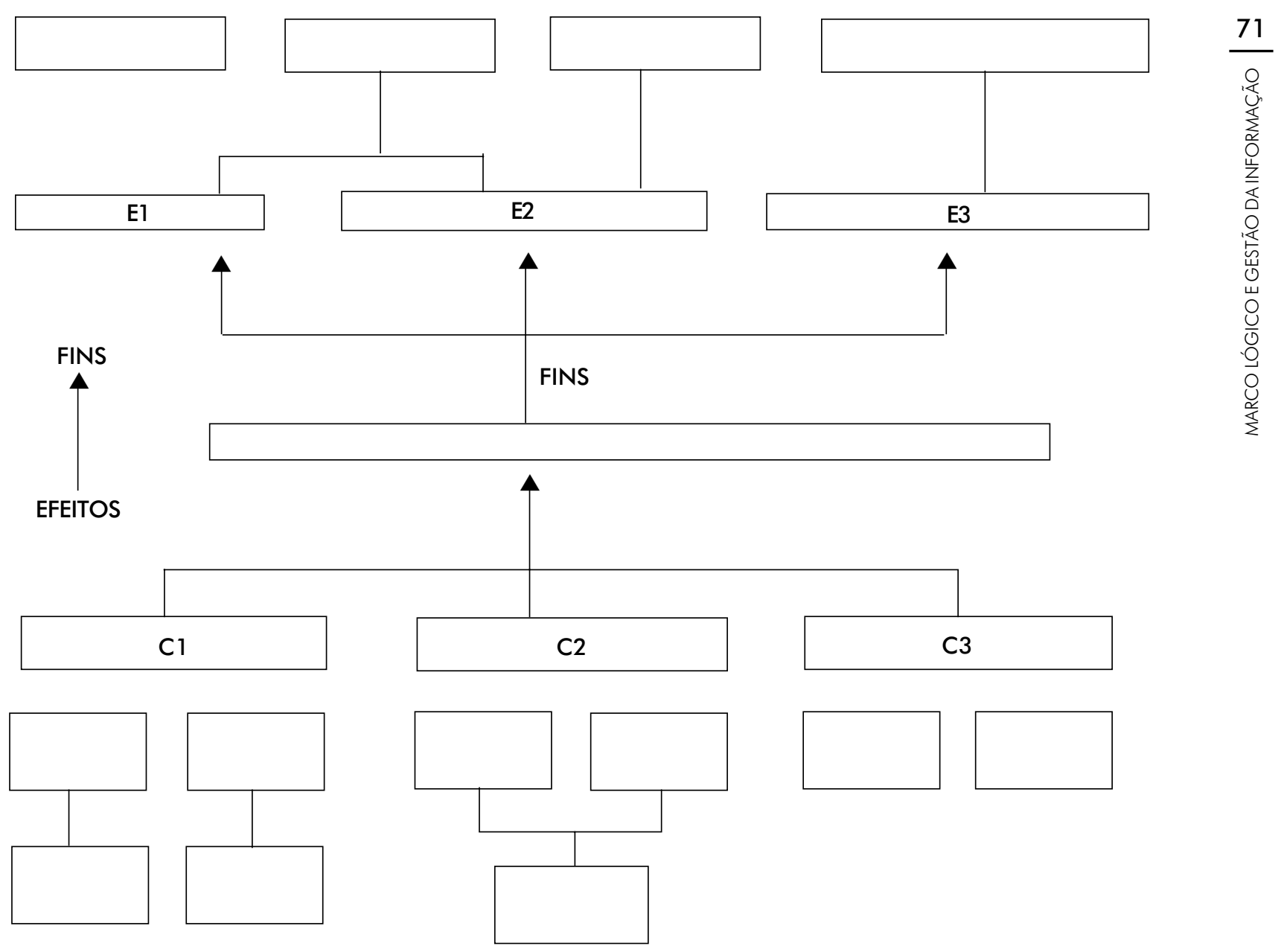

Figura 3. Árvore de objetivos.

Fonte: Scatolin, 2006.

Legenda: $C=$ causas e $E=$ efeitos.

Temos de enfatizar que não se deve confundir a MML com a Matriz do Marco Lógico, porque a metodologia compreende dez passos, na visão de Ortegon; Pacheco; Prieto (2005, p. 70): 1) análise dos atores envolvidos; 2) análise de problemas; 3) análise de objetivos; 4) análise de alternativas; 5) estrutura analítica do projeto; 6-9) matriz do marco lógico; 10) avaliação intermediária. A MML é "uma ajuda para refletir" (Scatolin, 2006); "uma ferramenta para pensar o processo de planejamento" (Scatolin, 2006), enquanto a matriz do Marco Lógico é o produto final do trabalho e consiste na descrição das atividades, dos componentes, dos propósitos e dos fins, e de seus indicadores, meios de verificação, hipóteses e riscos, como veremos no bloco a seguir.

Como se pode observar, os autores ora detalham em vários passos a $\mathrm{MML}$, ora em etapas. Todos que desejarem, porém, fazer a aplicação da metodologia, deverão basicamente rastrear a identificação do problema central e suas alternativas de solução e, na seqüência, proceder ao planejamento operacional prático para sua execução (Matriz do Marco Lógico), nossa próxima discussão. 


\section{Estrutura}

A MML, considerando os problemas a serem abordados, inclui uma Matriz de planejamento do projeto, que faz um sumário (esquema) representativo dos principais tópicos do projeto. Uma Matriz de Marco Lógico é um formato Standard, no qual estão incluídas as informações específicas para analisar uma determinada situação de planejamento (Quadro 3):

Quadro 3. Matriz do Marco Lógico.

\begin{tabular}{|c|l|l|l|}
\hline OBJETIVOS & INDICADORES & MEIOS DE VERIFICAÇÃO & HIPÓTESES \\
\hline FIM & & & \\
\hline PROPÓSITO & & & \\
\hline COMPONENTE & & & \\
\hline ATIVIDADES & & & \\
\hline
\end{tabular}

A Matriz do Marco Lógico é um sumário (desenho do plano) capaz de identificar os elementos, os fatores externos e as conseqüências esperadas para o problema central. Essa Matriz serve como uma ferramenta de planejamento, execução e monitoria de planos e projetos.

Uma Matriz elaborada pela MML utiliza-se como uma maneira prática de formular um plano, a partir de dois fundamentos técnicos. $\bigcirc$ primeiro fundamento consiste em esclarecer e definir, de maneira detalhada e lógica, os objetivos, os meios e as metas necessários para fazer com que os benefícios e o impacto do plano de desenvolvimento sejam sustentáveis. $\bigcirc$ segundo fundamento consiste em melhorar a implementação, a supervisão e monitoria do plano e a conseqüente avaliação, com indicadores que podem ser definidos para determinar se os objetivos foram atingidos.

\section{Vantagens de se utilizar a MML}

Conforme Penteado (2007), as vantagens da utilização da $M M L$, são que:

- Induz à objetividade na elaboração e descrição de programas e projetos;

- Propicia uma rápida e sintética visualização de programas e projetos;

- Possibilita uma rápida e fácil visualização dos principais fatores para acompanhamento e avaliação de programas e projetos;

- Tende a clarificar os fatores que dependem do desempenho do órgão executor e aqueles que estão fora de seu controle;

- Padroniza uma linguagem comum para as diversas fases de diferentes programas e projetos, independentemente de sua natureza.

\section{Desvantagens de se utilizar a MML}

Conforme Penteado (2007), as desvantagens da utilização da $M M L$, são que:

- Ignora o grau de inter-relacionamento entre diferentes programas e projetos;

- Ignora a dificuldade de se estabelecer objetivos superiores unívocos para programas e projetos na área pública.

\section{O PAPEL DA GESTÃO DA INFORMAÇÃO PARA A MML}

Sabemos que o conceito de Gestão da Informação não é, ainda, um conceito universalizado na literatura e, nem tampouco nos manuais de boas práticas das organizações. No entanto temos a clara percepção de que estamos diante de uma prática gerencial, social e ambiental, na medida em que se 
integra cada vez mais com as Ciências Econômicas e Ciências Ambientais, por intermédio de projetos inovadores.

Para os fins deste artigo, não é nosso interesse levantar conceitos sobre o termo, e sim, evidenciar, com alguma precisão e clareza, a sua aplicabilidade em termos de planejamento do desenvolvimento regional sustentável. Daí a interface entre a $M M L$ e a Gestão da Informação.

Em termos concretos, alguns membros colaboradores do Laboratório de Ecossocioeconomia da UFPR estão juntos no projeto de pesquisa intitulado: "Sistema de Informações Econômicas, Sociais e Ambientais para o Desenvolvimento Sustentável no Município de Tunas do Paraná 2008" (Caballero Nuñez et al., 2007). Esse trabalho servirá a um outro projeto de extensão universitária intitulado "Chapas preparadas a partir do refil picado de madeira assistidos por um processo de incubação a distância em Tunas do Paraná", sob a coordenação da Profa. Dra. Maria Aparecida Biason Gomes, do Departamento de Química da UFPR (Gomes, 2007). Esse projeto atendeu aos requisitos do Edital da Secretaria de Estado da Ciência, Tecnologia e Ensino Superior do Paraná (SETI), em seu Programa de Extensão Universitária Universidade Sem Fronteiras, Subprograma Incubadora dos Direitos Sociais (Edital SETI/PR No. 02/2007Curitiba/PR, Julho de 2007) e terá um ano para desenvolver um produto e/ou processo inovador sustentável a partir da madeira de pinus, abundante na região de Tunas do Paraná. A propósito, esse município é um dos mais pobres em termos de IDH no Estado/País. Trata-se, portanto, de uma grande oportunidade de se trabalhar com o novíssimo conceito de Ecossocioeconomia (Sachs, 2007), bem como com a Economia Socioambiental de Veiga (2007). E, tudo isso, é claro, com o aporte ou colaboração da área de Gestão da Informação da UFPR.

Daí que os objetivos geral e específicos, colimados para este projeto de Sistema de Informações Econômicas, Sociais e Ambientais para o Desenvolvimento Sustentável no Município de Tunas do Paraná 2008, são:

a) Objetivo Geral: desenvolver um sistema de informações econômicas, sociais e ambientais para o desenvolvimento sustentável para o Município de Tunas do Paraná - SIESADES TUNAS b) Objetivos específicos:

- consolidar os conhecimentos dos membros da equipe, nas áreas que integram a Ecossocioeconomia (Ciências Econômicas, Ciências Sociais e Ciências Ambientais) e uma maior destreza no uso de métodos e técnicas estatísticas e computacionais, e de tratamento espacial da informação;

- desenvolver um sistema de informações econômicas, sociais e ambientais, a partir de fontes de dados públicas e acessíveis, e o uso de programas computacionais livres;

- delinear a estrutura do sistema pela aplicação da MML, como método principal de análises, complementado, no que couber, do Método do Marco Lógico com Enfoque Apreciativo (ASDI, 2006) ou da Análise de Objetivos/Meios (Lu, 1975);

- organizar um sítio eletrônico (site) na Web, que permita uma ampla divulgação do sistema, juntamente com as informações referentes à Associação dos Municípios da Região Metropolitana de Curitiba (ASSOMEC), onde está localizado o município de Tunas do Paraná;

- organizar um curso de "Introdução ao Desenvolvimento Sustentável - teoria, aplicações e casos", a ser implementado na forma de curso de extensão universitária, utilizando o sistema criado pela equipe do projeto.

A Gestão da Informação deverá perpassar todas as fases do processo, desde a que antecede a produção até a comercialização do produto, respondendo a questões como: o que se deve produzir, para quem, a que preço, como e onde vender. Terá como incumbência também cuidar da proteção da propriedade intelectual/ industrial oriunda da Pesquisa e Desenvolvimento (P\&D) desenvolvida pela equipe multidisciplinar do projeto, além, é claro, de coletar os dados primários e secundários necessários em suas mais diversas fontes de informações. 
O que se vislumbra com o sistema de informações que ora está sendo criado é a formação de uma base sólida de conhecimentos e técnicas computacionais que possam ser compartilhadas entre todos os atores da cadeia produtiva da madeira de Tunas do Paraná, como de qualquer outra localidade em vias de desenvolvimento sustentável. Desse modo, será possível incrementar o processo de crescimento econômico, social e ambiental do Município de Tunas do Paraná no "mundo plano" de que nos fala Friedmann (2007).

Trata-se de um projeto multidisciplinar, com enfoque, também, na indissociabilidade entre ensino, pesquisa e extensão, voltado para a interação universidade-sociedade, numa perspectiva dialógica do cooperativismo, das práticas de responsabilidade social, das questões de cidadania, da geração do emprego e renda aos cidadãos menos favorecidos economicamente, para que se forme uma mentalidade de sustentabilidade local/regional do desenvolvimento no Município de Tunas do Paraná.

O Município de Tunas do Paraná é um dos municípios paranaenses de baixo IDH-M e com um crescente fluxo migratório, decorrente da existência de uma industrialização extrativista de madeira, principalmente de pinus e bracatinga. Além desses recursos naturais, o Município é abundante também em granito.

Sabe-se que o processo de reciclagem de resíduos tem aumentado consideravelmente nos últimos anos (Ferreira; Santana, 2007, p.631). Especificamente, no caso de Tunas do Paraná, os resíduos de madeira têm como destinação final a sua queima, gerando inúmeros problemas ao meio ambiente e não agregando valor à sociedade local. Daí que esse projeto (Gomes, 2007) de "Chapas preparadas..." procurará elevar a qualidade de vida dos cidadãos daquele município, ao desenvolver chapas de madeira que sirvam à produção de produtos e/ou processos inovadores com alto valor agregado, a partir do refil picado de madeira com a introdução de material polimérico (inovação tecnológica de produto e processo), proporcionando aos envolvidos um diferencial competitivo no mercado das chapas de madeira.

Enfim, nesse contexto, a equipe de colaboradores do projeto na área de Gestão da Informação terá um papel fundamental e poderá colaborar com o grupo de empreendedores, no tocante ao levantamento de informações para a tomada de decisões de natureza científica, tecnológica, técnica, econômica, comercial, administrativa, jurídica, social, ambiental, de benchmarking (de concorrência no mercado), de necessidades dos clientes, fornecedores e parceiros comerciais do empreendimento, com vistas ao desenvolvimento do produto inovador, de sua patenteabilidade no território nacional junto ao Instituto Nacional da Propriedade Industrial - (INPI) e, conseqüentemente, à sua comercialização ou transferência de tecnologia.

\section{CONSIDERAÇÕES FINAIS}

Atualmente, as grandes instituições e, também, - Governo do Estado do Paraná estão se utilizando da MML para a formulação e avaliação de suas políticas públicas macro e micro econômicas. Também temos conhecimento de que a ASDI está incentivando o uso da MML com um enfoque apreciativo, o que, por si só, iá daria discussão para outro artigo, que reforça a idéia de aplicação da MML.

Quanto ao crescimento econômico brasileiro, Scatolin (2006) sintetiza como segue:

O preço do capital importa (crescimento ajuda a projetar o investimento e o contrário, não). $\bigcirc$ País deve investir em Educação e não somente, em anos de escolaridade. No tocante à Inovação, a estratégia do aprendizado e o cathing-up são os principais determinantes do crescimento no longo prazo para países em desenvolvimento. Institucionalizar o processo de diagnóstico nas instituições é importante, oferecendo incentivos que favoreçam investimentos, crescimento e distribuição. Valorizar ainda mais a Geografia, pois ela importa - a dinâmica da estrutura produtiva ajuda no crescimento.

AMML nos ajuda a compreender melhor o que é causa e o que é conseqüência de muitos problemas. Se o objetivo de alguém é o de alcançar um crescimento elevado, portanto, na ótica da MML o desafio maior será o de transformar a árvore de problemas em árvore de soluções, a partir dos seus objetivos que, perante a MML são resultados mensuráveis e observáveis no contexto da metodologia.

Por fim, concluímos que a Gestão da Informação tem um papel fundamental para a MML no tocante à coleta, tratamento, disseminação e uso das informações socioeconômicas e ambientais, para o desenvolvimento sustentável. 


\section{REFERÊNCIAS}

AGÊNCIA SUECA DE COOPERAÇÃO INTERNACIONAL PARA O DESENVOLVIMENTO (ASDI). Enfoque del marco lógico: con un enfoque apreciativo. Suécia: ASDI, 2006.

AGÊNCIA SUECA DE COOPERAÇÃO INTERNACIONAL PARA O DESENVOLVIMENTO (ASDI). Um resumo da teoria por trás do método do marco lógico. Portugal: ASDI, 2003.

AMARAL FILHO, J. Desenvolvimento regional endógeno em um ambiente federalista. Planejamento e Políticas Públicas, n. 14, p.36-40, 1996.

CABALLERO NUNEZ, B.E. et al. Sistema de informações econômicas, sociais e ambientais para o desenvolvimento sustentável do Município de Tunas do Paraná 2008. Curitiba: UFPR, 2007. $4 \mathrm{p}$. Projeto de pesquisa aplicada em andamento e vinculado ao Projeto de Gomes, 2007.

CONCEIÇÃO, R.J. O método de marco lógico e o processo de planejamento do desenvolvimento. In: CONCEIÇÃO, R.J. Planejamento regional do desenvolvimento sustentável para a Associação de Municípios dos Campos Gerais (AMCG) no Estado do Paraná [2005/2015]: uma aplicação do método de marco lógico. Curitiba: UFPR, 2007. 28p. Projeto de pesquisa apresentado, à disciplina Monografia I do Curso de Ciências Econômicas da UFPR.

CONCEIÇÃO, R.J.; CABALLERO NUNEZ, B.E. Planejamento regional no Estado do Paraná: uma aplicação do método de objetivos e meios. In: ENCONTRO NACIONAL DA ASSOCIAÇÃO BRASILEIRA DE ESTUDOS REGIONAIS E URBANOS, 4., 2006. Anais... Foz do lguaçu, 2006.

FERREIRA, F.P; SANTANA, R.M.C. Importância da reciclagem dos plásticos pela ótica do ensino à distância. In: JORNADAS DE JÓVENES INVESTIGADORES DE LA AUGM, 15., 2007. Anales... Asunción: s.n., 2007. 631 p.

FRIEDMAN, T.L. O mundo é plano: uma breve história do século XXI. 2.ed. Rio de Janeiro: Objetiva, 2007. 557p.
GOMES, M.AB. et al. Chapas preparadas a partir de refil picado de madeira assistidos por um processo de incubação à distância em Tunas do Paraná. Curitiba: UFPR: SETI, 2007. 9p. Projeto de Extensão Universitária, vinculado ao Programa Universidade Sem Fronteiras - SETI-PR - Subprograma: Incubadora de Direitos Sociais - Edital n. 02/2007.

LIMA, A.M. O método do marco lógico: avaliação e definição de programas e projetos públicos. Porto Alegre: 2003.

LU, M. Planejamento regional - urbano e análise de sistemas: formalização de um modelo articulativo. São Paulo: FIPE/IPEA/ BID, 1975.

ORTEGÓN, E.; PACHECO, J.F.; PRIETO, A. Metodologia del marco lógico para la planificación, el seguimiento y la evaluación de proyectos y programas. Santiago de Chile: CEPAL/ILPES, 2005. 124p. (Serie manuales; 42).

PENTEADO, P. Elaboração de programas e projetos. Disponível em: < http://www.ufba.br/ paulopen/logtex.html>. Acesso em: 8 jun. 2007

PEREIRA, E.C. Metodologias para gestão da informação. Transinformação, v. 15, n.3, p.303-318, 2003.

SACHS, I. Rumo à ecossocioeconomia: teoria e prática do desenvolvimento. São Paulo: Cortez, 2007. 472p.

SCATOLIN, F.D. Disciplina: Metodologia para formulação e avaliação de políticas públicas. In: UNIVERSIDADE FEDERAL DO PARANÁ. Setor de Ciências Sociais Aplicadas. Departamento de Contabilidade. Curso de Especialização em Formulação e Gestão de Políticas Públicas - Turma A Curitiba, UFPR/S.A/DECONT: Escola de Governo, 2006. Apontamentos de aulas.

VEIGA, J.E. A emergência socioambiental. São Paulo: Ed. SENAC São Paulo, 2007. 138p.

ZAPATA, M.E. Taller sobre marco lógico - Fortaleza, 20 al 22 de marzo de 2006. IFLA/LAC Notícias, n.48, p. 13-14, 2006. 
